\title{
Homology Modeling and Active Sites of PolyMG-specific Alginate Lyase from Stenotrophomonas maltophilia KJ-2
}

\author{
Hee Sook Kim* \\ Department of Food Science and Biotechnology, Kyungsung University, Busan 608-736, Korea
}

Received December 12, 2013 /Revised January 20, 2014 / Accepted January 23, 2014

\begin{abstract}
Alginates are linear acidic polysaccharides composed with (1-4)-linked a-L-guluronic acid and B-Dmannuronic acid. Alginate can be degraded by diverse alginate lyases, which cleave the alginate using a $\beta$-elimination reaction and produce unsaturated uronate oligomers. A gene for a polyMG-specific alginate lyase possessing a novel structure was previously identified and cloned from Stenotrophomonas maltophilia KJ-2. Homology modeling of KJ-2 polyMG-specific alginate lyase showed it belongs to the PL6 family, whereas three Azotobacter vinelandii polyMG lyases belong to the PL7 family of polysaccharide lyases. From ${ }^{1} \mathrm{H}-\mathrm{NMR}$ spectra data, KJ-2 polyMG lyase preferably degraded the M- $\beta(1-4)-\mathrm{G}$ glycosidic bond than the G-a(1-4)-M glycosidic bond. Seventeen mutants were made by site-directed mutagenesis, and alginate lyase activity was analyzed. Lys220Ala, Arg241Ala, Arg241Lys, and Arg265Ala lost alginate lyase activity completely. Arg155Ala, Gly303Glu, and Tyr304Phe also lost the activity by 60.7-80.1\%. These results show that Arg155, Lys220, Arg241, Arg265, Gly303, and Tyr304 are important residues for catalytic activity and substrate binding.
\end{abstract}

Key words : Alginate, alginate lyase, polyMG-specific alginate lyase, homology modeling, site-directed mutagenesis

\section{서 론}

해조류 중 갈조류(Phaeophyceae)에는 다시마목(Laminariales), 모자반목(Fucales), 솜털목(Ectocarpales) 등 19종의 목 으로 분류되며 그 중, 다시마목에는 Macrocystis속, Laminaria 속 및 Undaria속들이 있고, 모자반목에는 Sargassum속 및 Ascophyllum속 등이 있다. 해조류 중 갈조류는 거대조류로서 바이오에탄올로 전환되기 쉬운 laminaran (glucan의 일종)과 mannitol을 함유하고 있으며 그 외에 알긴산, cellulose 및 fucoidan 등은 세포벽 matrix를 이루는 주된 성분이다[6, 27, 31]. 알긴산은 갈조류 건조구성물의 $14-37 \%$ 차지하며 신재생 바이 오에너지를 생산하기 위한 연구들이 진행되고 있다 $[3,5,25$, 30]. 해조류 유래 알긴산은 $\beta$-D-mannuronate $(\mathrm{M})$ 및 a-L-guluronate $(\mathrm{G})$ 가 $a(1-4)$ 또는 $\beta(1-4)$ 결합을 한 선형 산성다당류 이다(Fig. 1)[7, 9, 12]. 알긴산을 바이오에 탄올로 전환시키기 위해서는 먼저 당화시켜야 하며 산가수분해 또는 효소분해가 필요하다. 알긴산을 탄소원으로 사용하는 미생물들은 여러 종 류의 알긴산 분해효소들(alginate lyase)을 가지며 이 효소들은

\footnotetext{
*Corresponding author

Tel : +82-51-663-4713, Fax : +82-51-622-4986

E-mail : hskim@ks.ac.kr

This is an Open-Access article distributed under the terms of the Creative Commons Attribution Non-Commercial License (http://creativecommons.org/licenses/by-nc/3.0) which permits unrestricted non-commercial use, distribution, and reproduction in any medium, provided the original work is properly cited
}

당과 당 사이 결합부분을 $\beta$-제거반응으로 분해하는 반응을 촉매하고 비환원 말단에 이중결합을 가진 불포화된 당을 생성 한다 $[1,4,16]$. PolyM block을 분해하는 polyM-specific lyase (EC 4.2.2.3), polyG block을 분해하는 polyG-specific lyase (EC 4.2.2.11) 및 올리고 알긴산의 비환원 말단부터 불포화우론 산 단당체로 분해하는 oligoalginate lyase (EC 4.2.2.-)들이 클 로닝되어 특성이 보고되었으며 $[10,13,17,22,23]$ 본 실험실에 서 polyMG block을 분해하는 polyMG-specific lyase (EC 4.2.2.-, AFC88009)를 보고한 바 있다[18]. CAZy (Carbohydrateactive enzyme, http://www.cazy.org/) 데이터베이스에서는 다당류 분해효소류(polysaccharide lyases family, PLs family) 의 구조를 촉매자리와 탄수화물 결합모듈을 토대로 23 종류로 분류하고 있으며, 알긴산 내부분해효소들은 주로 PL5 family ((a/a)6 barrel), PL6 family (parallel $\beta$-helix) 또는 PL7 family ( $\beta$-jelly roll)에 속하며, 알긴산 외부분해효소들은 PL15 family (alpha/alpha-barrel + anti-parallel beta-sheet) 또는 PL21 family (N-terminal alpha-helical domain, a central two-layered beta-sheet domain, and a C-terminal domain forming a two-layered beta-sheet)에 속하는 것으로 알려져 있다[19].

본 연구에서는 Stenotrophomonas maltophilia KJ-2 균주의 polyMG-specific lyase가 D-mannuronate- $\beta(1-4)$-L-guluronate 결합과 L-guluronate- $a(1-4)$-D-mannuronate 결합 중 어 느 결합에 특이적인지 알기 위하여 ${ }^{1} \mathrm{H}-\mathrm{NMR}$ spectra를 측정, 분석하였으며 homology-modeling을 이용한 분자구조 예측 및 site-directed mutagenesis 방법을 이용한 효소활성자리를 예측하였다. 
Table 1. The chemical composition of guluronate and mannuronate of used substrates

\begin{tabular}{lccccccccc}
\hline Designation & $\mathrm{F}_{\mathrm{G}}$ & $\mathrm{F}_{\mathrm{M}}$ & $\mathrm{F}_{\mathrm{GG}}$ & $\mathrm{F}_{\mathrm{GM}, \mathrm{MG}}$ & $\mathrm{F}_{\mathrm{MM}}$ & $\mathrm{F}_{\mathrm{GGM}}$ & $\mathrm{F}_{\mathrm{MGM}}$ & $\mathrm{F}_{\mathrm{GGG}}$ & $\mathrm{DP}_{n}{ }^{\mathrm{a}}$ \\
\hline Alginate & 0.38 & 0.62 & 0.11 & 0.27 & 0.35 & 0.06 & 0.21 & 0.05 & $30-40^{b}$ \\
PolyG & 0.87 & 0.13 & 0.87 & 0.01 & 0.11 & 0.01 & 0.01 & 0.86 & 19 \\
PolyM & 0.11 & 0.89 & 0.01 & 0.10 & 0.79 & 0.01 & 0.09 & 0.00 & 19 \\
PolyMG & 0.42 & 0.58 & 0.02 & 0.41 & 0.16 & 0.02 & 0.36 & 0.00 & 23 \\
\hline
\end{tabular}

${ }^{a} \mathrm{DP}_{\mathrm{n}}$ indicates the average degree of polymerization.

${ }^{\mathrm{b}}$ Alginate $(\mathrm{cps}=3,500)$ was degraded to a $\mathrm{DP}_{n}=30-40$ by mild acid hydrolysis [2].

\section{재료 및 방법}

\section{효소 및 시약}

기질로 사용한 알긴산(3500 cps)은 Sigma 사(St. Louis, MO, USA)에서 구매하였으며 polyM block, polyG block 및 polyMG block은 Haug 등의 방법[11]에 따라 준비하였고 각각 의 구성성분은 Table 1 과 같았다. 단백질 정제를 위한 $\mathrm{Ni}-$ Sepharose는 Amersham Biosicences (Piscataway, NJ, USA) 에서, HiTrap desalting column은 GE Healthcare Bio-sciences 사(Piscataway, NJ, USA)에서 구입하였다. Site- directed mutagenesis kit는 Stratagene 제품(Santa Clara, CA, USA)을 사 용하였으며 plasmid 정제 kit는 GeneAll 제품(Seoul, Korea)을 사용하였다. NMR 시료를 용해시키는 $\mathrm{D}_{2} \mathrm{O}$ 및 내부표준 시약 인 TMSP (0.75\% 3-(trimethylsilyl) propionic-2,2,3,3-d4 acid, sodium salt in $\mathrm{D}_{2} \mathrm{O}$ )는 Sigma 사(St. Louis, $\mathrm{MO}, \mathrm{USA}$ )에서 구입하였다.

\section{PolyMG lyase에 의하여 분해된 polyMG 분해물 생성 및 FPLC 분석}

본 연구에서 사용된 알긴산 분해효소는 이전에 클로닝하였 던 Stenotrophomonas maltophilia KJ-2의 polyMG lyase를 사용 하였다[18]. 먼저 pET21b/KJ-2_alyMG plasmid DNA를 가지 는 E. coli $\mathrm{BL} 21(\mathrm{DE} 3)$ 균주를 ampicillin 함유 $\mathrm{LB}$ 배지에 배양하 고 OD값이 0.4-0.6이 되었을 때 IPTG로 단백질 발현을 유도하 였다. 24시간 뒤 세포를 파쇄하고 Ni-sheparose column으로 정제, 탈염한 다음 여러 개의 vial에 $200 \mu \mathrm{g}$ 효소단백질 용액을 나누어 넣고 동결건조한 다음 $4^{\circ} \mathrm{C}$ 에 저장하여 두고 실험에 사용하였다. 기질로 사용한 polyMG block은 sodium alginate 를 Haug 등 방법[11]에 따라 산가수분해하여 얻은 다음 동결 건조하고 $\mathrm{D}_{2} \mathrm{O}$ 로 녹인 다음 다시 동결건조하여 사용하였다. $\mathrm{D}_{2} \mathrm{O}$ 를 이용하여 $1 \%$ polyMG 기질용액으로 만들었다. $\mathrm{D}_{2} \mathrm{O}$ 에 녹인 $1 \%$ polyMG 기질 용액을 $800 \mu \mathrm{l}$ 씩 동결건조된KJ-2 polyMG lyase가 들어있는 microtube에 넣은 다음 $40^{\circ} \mathrm{C}$ 에서 반응시키면서 지정된 시간에 꺼내어 꼻인 다음 원심분리하여 NMR 시료로 하였다. 또한 polyMG block 분해물은 Superdex peptide column 100/300 GL (GE Healthcare, Piscataway, NJ, $\mathrm{USA}$ )과 $235 \mathrm{~nm}$ 검출기를 장착시킨 $\mathrm{FPLC}$ 를 사용하여 분해정 도를 분석하였다.
PolyMG block 효소분해물의 $1 \mathrm{H}-\mathrm{NMR}$ spectra 분석

${ }^{1} \mathrm{H}-\mathrm{NMR}$ 분석을 위한 시료의 준비는 Kam 등의 방법[15]에 따랐다. $400 \mathrm{~Hz}{ }^{1} \mathrm{H}-\mathrm{NMR}$ spectroscopy (ECX-NMR, JEOL Ltd., Tokyo, Japan)로 측정하였으며 NMR 스펙트럼은 Grasdalen [9] 및 Zhang 등[33]의 방법에 따라 해석하였다. 시간별 효소반응액 $800 \mu 1$ 에 내부표준물질인 TMSP $(0.75 \%$ 3-(trimethylsilyl)-2,2' ${ }^{\prime}, 3,3^{\prime}$-tetradeuteropropionic acid, Na salt) 10 $\mu 1$ 를 가하여 측정하였으며 data 수집은 $80^{\circ} \mathrm{C}$ 에서 행하였다. 시료의 spinning, proton spectral width, scan 횟수, relaxation delay, proton pulse angle, 및 data 수집시간 등은 각각 15 $\mathrm{Hz},-5 \sim 15 \mathrm{ppm}, 64,5 \mathrm{~s}, 90^{\circ}$, 및 $4.098 \mathrm{~s}$ 이었다.

\section{$\mathrm{KJ}-2$ polyMG lyase 단백질의 상동성 모델}

발현된 KJ-2 polyMG lyase 단백질(GenBank accession No. $\mathrm{AFC} 88010)[18]$ 의 3-D 입체구조를 예측하기 위하여 SwissModel workspace (http://swissmodel.expasy.org/) 및 Modeller 7v7 program (http://salilab.org/modeller/)을 사 용하였다. 상동성 모델링의 주형으로는 Pedobacter heparinus로 부터 얻은 chondroitinase $B$ 의 X-ray 결정구조(pdb code: 1ofl) 를 사용하였다. Chondroitinase B 결정구조 위에 $\mathrm{KJ}-2$ polyMG lyase 모델을 겹치고 활성부위를 구성하는 아미노산 잔기를 나타내기 위하여 Python Molecule Viewer (PMV version 1.5.4, http://mgltoos.scripps.edu/)를 사용하였다.

\section{PolyMG lyase의 활성부위를 찾기 위한 site-directed mutagenesis}

Pedobacter heparinus chondroitinase B 아미노산 서열(1ofl) 과 KJ-2 polyMG lyase의 아미노산 서열(AFC88009)을 PSIblastp 방법을 이용하여 정렬하고 chondroitinase B 결정구조 와 KJ-2 polyMG lyase 모델을 겹쳐봄으로써 active site를 추정 하였으며 돌연변이시킬 목적 아미노산들로 지정하였다. PCR 기술을 이용하여 polyMG lyase를 돌연변이시켰으며 사용한 primer들의 염기서열은 Table 2 와 같았다. pET21b 발현vector 에 돌연변이 효소유전자들을 삽입한 뒤, 대장균 BL21(DE3) 균주에 형질전환시키고 $0.7 \mathrm{mM} \mathrm{IPTG를} \mathrm{이용하여} \mathrm{단백질들을}$ 과발현시켰다. 원심분리한 균에 lysozyme 용액 $(10 \mathrm{mg} / \mathrm{ml}$ in $50 \mathrm{mM}$ Tris- $\mathrm{HCl}, \mathrm{pH} 8.0$ )를 가하여 $-70^{\circ} \mathrm{C}$ 냉동고에 얼렸다 녹였다를 반복하여 cell lysate를 얻었다. Cell lysate들에 돌연 
Table 2. Mutation sites and primer sequences for site-directed of polyMG-specific lyase from Stenotrophomonas maltophilia KJ-2

\begin{tabular}{|c|c|c|}
\hline Primer & Direction & $5^{\prime}$ - oligonucleotide sequence - $3^{\prime}$ \\
\hline Val152Arg & $\begin{array}{l}\text { forward } \\
\text { reverse }\end{array}$ & $\begin{array}{l}\text { CAACGCGGGGCCCACCGTGCGCGTAGTGCGCGATGTCACGC } \\
\text { GCGTGACATCGCGCACTACGCGCACGGTGGGCCCCGCGTTG }\end{array}$ \\
\hline Arg155Ala & $\begin{array}{l}\text { forward } \\
\text { reverse }\end{array}$ & $\begin{array}{l}\text { CCACCGTGGTGGTAGTGGCCGATGCCACGCAGGGCC } \\
\text { GGCCCTGCGTGGCATCGGCCACTACCACCACGGTGG }\end{array}$ \\
\hline Asn181Ala & $\begin{array}{l}\text { forward } \\
\text { reverse }\end{array}$ & $\begin{array}{l}\text { CACGCCCTGCGCTGGGCGTCGCCGGCGGTGAAACCCTCCGCATC } \\
\text { GATGCGGAGGGTTTCACCGCCGGCGACGCCCAGCGCAGGGCGTG }\end{array}$ \\
\hline Lys220Ala & $\begin{array}{l}\text { forward } \\
\text { reverse }\end{array}$ & $\begin{array}{l}\text { GAAACCGAGATCATCAGCAGCGCATCCGGGGGCAACACCTATCGC } \\
\text { GCGATAGGTGTTGCCCCCGGAT } \underline{G C G C T G C T G A T G A T C T C G G T T T C ~}\end{array}$ \\
\hline Lys220Arg & $\begin{array}{l}\text { forward } \\
\text { reverse }\end{array}$ & $\begin{array}{l}\text { GAAACCGAGATCATCAGCAGCCGCTCCGGGGGCAACACCTATCGC } \\
\text { GCGATAGGTGTTGCCCCCGGAGCGGCTGCTGATGATCTCGGTTTC }\end{array}$ \\
\hline Arg241Ala & $\begin{array}{l}\text { forward } \\
\text { reverse }\end{array}$ & $\begin{array}{l}\text { TCTGCCGGCGCACTCACACTGGCCCATGGCAACGGCAACCGGGTG } \\
\text { CACCCGGTTGCCGTTGCCATGGGCCAGTGTGAGTGCGCCGGCAGA }\end{array}$ \\
\hline Arg241Lys & $\begin{array}{l}\text { forward } \\
\text { reverse }\end{array}$ & $\begin{array}{l}\text { TCTGCCGGCGCACTCACACTGAAACATGGCAACGGCAACCGGGTG } \\
\text { CACCCGGTTGCCGTTGCCATGTTTCAGTGTGAGTGCGCCGGCAGA }\end{array}$ \\
\hline His242Ala & $\begin{array}{l}\text { forward } \\
\text { reverse }\end{array}$ & $\begin{array}{l}\text { GCGCACTCACACTGCGCGCTGGCAACGGCAACCGGG } \\
\text { CCCGGTTGCCGTTGCCAGCGCGCAGTGTGAGTGCGC }\end{array}$ \\
\hline Asn244Ala & $\begin{array}{l}\text { forward } \\
\text { reverse }\end{array}$ & $\begin{array}{l}\text { CACTCACACTGCGCCATGGCGCCGGCAACCGGGTGATCGAC } \\
\text { GTCGATCACCCGGTTGCCGGCGCCATGGCGCAGTGTGAGTG }\end{array}$ \\
\hline Arg265Ala & $\begin{array}{l}\text { forward } \\
\text { reverse }\end{array}$ & $\begin{array}{l}\text { GGCCGGCACCGGGGGCGTGGCCATCATCAACGGCGACCAG } \\
\text { CTGGTCGCCGTTGATGATGGCCACGCCCCCGGTGCCGGCC }\end{array}$ \\
\hline Arg265Lys & $\begin{array}{l}\text { forward } \\
\text { reverse }\end{array}$ & $\begin{array}{l}\text { CAAGGCCGGCACCGGGGGCGTGAAAATCATCAACGGCGACCAGATC } \\
\text { GATCTGGTCGCCGTTGATGATTTTCACGCCCCCGGTGCCGGCCTTG }\end{array}$ \\
\hline Asn268Ala & $\begin{array}{l}\text { forward } \\
\text { reverse }\end{array}$ & $\begin{array}{l}\text { CGTGCGCATCATCGCCGGCGACCAGAT } \\
\text { ATCTGGTCGCCGGCGATGATGCGCACG }\end{array}$ \\
\hline Asn268Asp & $\begin{array}{l}\text { forward } \\
\text { reverse }\end{array}$ & 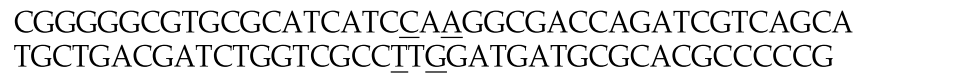 \\
\hline Gly303Glu & $\begin{array}{l}\text { forward } \\
\text { reverse }\end{array}$ & $\begin{array}{l}\text { ATCCCCCGCTGTCCGAATACGCACCGGTAGTG } \\
\text { CACTACCGGTGCGTAATCGGACAGCGGGGGAT }\end{array}$ \\
\hline Tyr304Phe & $\begin{array}{l}\text { forward } \\
\text { reverse }\end{array}$ & $\begin{array}{l}\text { CCCCGCTGTCCGGTTTCGCACCGGTAGTGAAT } \\
\text { ATTCACTACCGGTGCGAAACCGGACAGCGGGG }\end{array}$ \\
\hline His329Ala & $\begin{array}{l}\text { forward } \\
\text { reverse }\end{array}$ & $\begin{array}{l}\text { GATCAGCTTCGGCGTGGGCGCTGATGAAGCCAAGGGCATCGTG } \\
\text { CACGATGCCCTTGGCTTCATCAGCGCCCACGCCGAAGCTGATC }\end{array}$ \\
\hline Lys333Ala & $\begin{array}{l}\text { forward } \\
\text { reverse }\end{array}$ & $\begin{array}{l}\text { CGTGGGCCATGATGAAGCCGCGGGCATCGTGGTGGCCGCC } \\
\text { GGCGGCCACCACGATGCCCECGGCTTCATCATGGCCCACG }\end{array}$ \\
\hline
\end{tabular}

Val152Arg means that valine residue on the $152^{\text {nd }}$ amino acid sequence was changed to arginine residue. Underlined letters indicate the replaced nucleotide bases.

변이된 효소단백질이 함유되어 있는지 SDS-PAGE 전기이동 법으로 확인하였으며 alginate lyase 활성은 $\beta$-제거반응에 의 하여 생성되는 비환원말단의 이중결합을 TBA method [26]로 확인하였다. KJ-2 polyMG lyase 효소활성에 사용된 기질은 PolyM, polyG 및 polyMG block이며 그 구성은 Table 1에 나 타난 바와 같다.

\section{결과 및 고찰}

PolyMG lyase에 의하여 분해된 polyMG block의 ${ }^{1} \mathrm{H}-$ NMR spectra의 분석

해조류의 알긴산은 Fig. 1에서와 같이 D-mannuronate가 약
20 개 정도 $\beta(1-4)$ 결합한 polyM block, L-guluronate가 약 20 개 정도 $\mathrm{a}(1-4)$ 결합한 polyG block 그리고 D-mannuronate와 L-guluronate가 MGMGGMGMM과 같이 무작위적으로 결합 되어 있는 polyMG block으로 구성되어 있다 $[9,11]$. Sphingomonas sp. A1 및 Pseudomonas sp. KS-408 균주의 polyM lyase 는 $\mathrm{M}-\mathrm{M}$ 및 $\mathrm{M}-\mathrm{G}$ 결합을 분해하여 $\beta(1-4)$ 결합에 특이적인 효 소로 보고되었다[15, 32]. 반면 Corynebacterium sp. Aly1 및 Streptomyces sp. Alg5 균주의 polyG lyase는 G-G 및 G-M 결합 을 분해하여 $a(1-4)$ 결합에 특이적인 효소이다[17, 22]. Momma 등[21]이 보고한 Sphingomonas sp. A1의 알긴산 분해효소 관련 gene cluster를 보면 polyM lyase, polyG lyase 및 oligoalginate lyase 유전자를 가지고 있는 반면, Stenotrophomonas mal- 


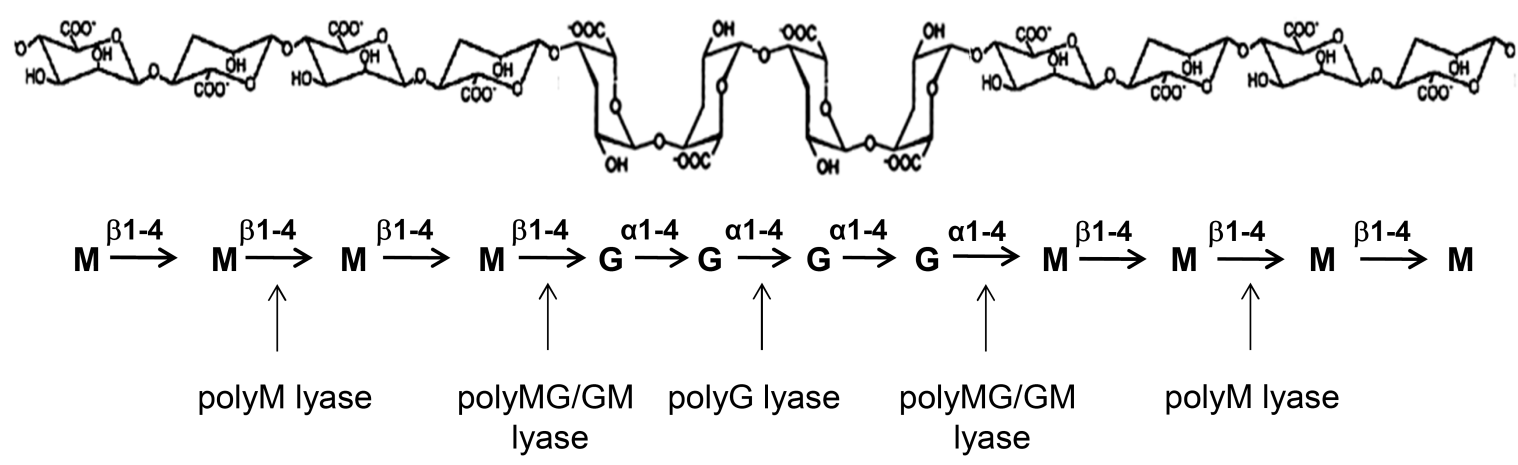

Fig. 1. Schematic diagram of diverse endolytic cleavage by alginate lyases. Alginate is a linear polysaccharide which $\beta$-D-mannuronate $(\mathrm{M})$ and its epimer, a-L-guluronate $(\mathrm{G})$, are covalently (1-4)-linked. Upward arrows mean cleavage sites by substrate specific alginate lyases.

tophilia 균주들의 genome (http://www.ncbi.nlm.nih.gov/bioproject)을 구성하는 유전자들을 분석한 결과 polyM lyase 및 oligoalginate lyase와 단백질서열이 상동성이 있는 유전자 만을 가지고 있었다. 그러나 본 연구실에서 분리한 Stenotrophomonas maltophilia KJ-2 균주로부터 얻은 알긴산 분해효소는 polyM block $(9.5 \%)$ 또는 polyG block $(8.7 \%)$ 보다는 polyMG block $(100 \%)$ 에 기질특이성이 있어 polyMG lyase라고 이름
을 붙였다[18]. PolyMG block 중 M- $\beta(1-4)-G$ 을 분해하는지 G-a(1-4)-M을 분해하는지 알아보기 위하여 KJ-2 polyMG lyase를 기질인 polyMG 용액에 넣고 지정된 시간동안 반응 을 시킨 후 ${ }^{1} \mathrm{H}-\mathrm{NMR}$ spectra를 측정한 결과는 Fig. 2 와 같았 다. 기질로 사용한 polyMG block의 NMR 분석 결과는 Table 1 에와 같이 GG fraction $2 \%, \mathrm{MM}$ fraction $16 \%$ 및 $\mathrm{MG}+\mathrm{GM}$ fraction $82 \%$ 를 함유하고 있었다. KJ-2 lyase에 의한 polyMG

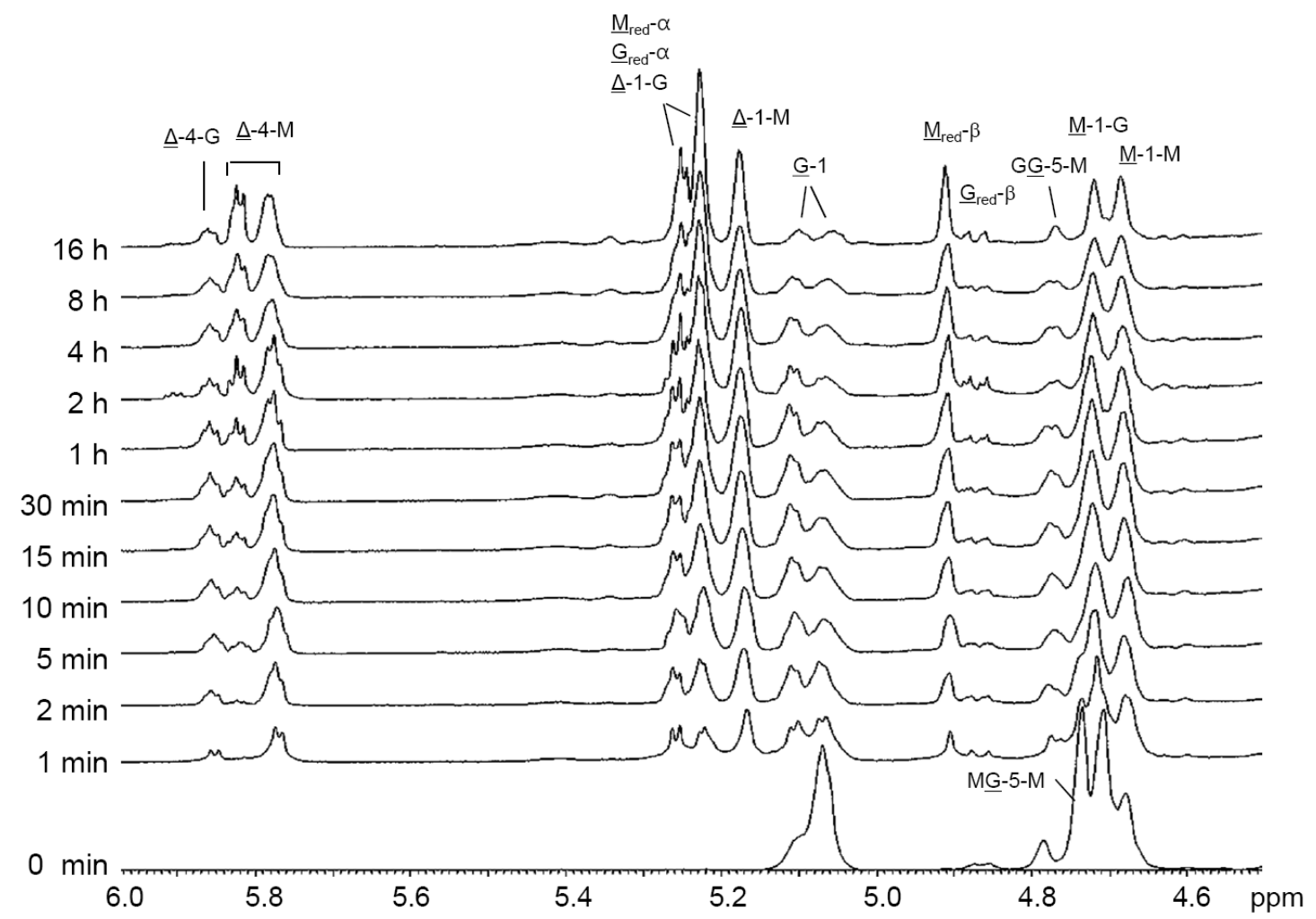

Fig. 2. ${ }^{1} \mathrm{H}-\mathrm{NMR}$ spectra of time dependent substrate degradation by KJ-2 polyMG-specific lyase. Each $800 \mu 1 \%$ polyMG block solution in $\mathrm{D}_{2} \mathrm{O}$ was added to lyophilized enzyme in each vial and incubated at $40^{\circ} \mathrm{C}$. After incubation for indicated time, reaction mixture was boiled to remove the activity and moved into NMR tube. The signals originated from the underlined residue. The numbers denote proton causing the signal. $\mathrm{M}$ or $\mathrm{G}$ without underline indicates neighbor residue. 
block 분해물의 NMR spectra를 보면 $\mathrm{M}-1-\mathrm{M}$ peak (4.67 ppm) 는 거의 감소하지 않았으며 GG-5-M peak (4.78 ppm) 역시 거의 감소하지 않아 KJ-2 polyMG lyase는 M- $\beta(1-4)-M$ 및 G-a (1-4)-M 결합을 분해하지 않는 것으로 보인다. PolyMG block 의 내부에 있는 G-1 peak (5.07 ppm)이 감소한 이유는 G앞에 있는 결합의 $\beta$-제거 반응에 의해 불포화 비환원말단 $(\triangle)$ 이 되 었기 때문이며 그 대신 $\triangle-4-G(5.85 \mathrm{ppm}), \triangle-1-\mathrm{G}$ (5.82-5.76 $\mathrm{ppm}), \triangle-1-\mathrm{M}(5.25-5.22 \mathrm{ppm})$ 및 $\triangle-4-\mathrm{M}$ (5.17 ppm) peak들 이 증가한 것으로 설명할 수 있다. $4.74 \mathrm{ppm}$ 의 MG-5-M peak 가 거의 모두 사라졌는데 이는 M- $\beta(1-4)-G$ 결합이 분해되어 환원 말단이 $\mathrm{M}\left(\mathrm{M}_{\mathrm{red \beta} \beta}, 4.90 \mathrm{ppm}\right.$ 및 $\left.\mathrm{M}_{\mathrm{reda}}, 5.25-5.22 \mathrm{ppm}\right)$ 인 올리고머와 비환원 말단이 $\triangleq(\triangle-1-\mathrm{M}, 5.25-5.22 \mathrm{ppm}$ 및 $\triangleq$ -4-M, $5.17 \mathrm{ppm}$ )인 올리고머가 생성된 때문이다. 또한 기질의 분해가 끝난 16 시간 후 생성물의 경우를 보면 $4.71 \mathrm{ppm}$ 의
M-1-G peak가 어느 정도 남아 있고 4.87-4.87 ppm의 $\mathrm{G}_{\mathrm{red} \beta}$ peak의 증가가 거의 없는 것을 보아 KJ-2 polyMG lyase는 $\mathrm{M}-\beta(1-4)-\mathrm{G}$ 결합은 분해했지 만 $\mathrm{G}-\mathrm{a}(1-4)-\mathrm{M}$ 결합은 분해하지 못하였음을 알 수 있었다. 토양 박테리아인 Azotobacter vinelandii는 $\mathrm{M}$ 과 $\mathrm{G}$ 를 함유하는 아세틸알긴산을 생산하는 균주 로 먼저 mannuronan을 생산한 다음 C-5-epimerase를 이용 하여 mannuronan을 구성하는 $\mathrm{M}$ 의 일부분을 $\mathrm{G}$ 로 전환시키 며 세 종류(AlyA1, AlyA2 및 AlyA3)의 polyMG lyase를 가진 다고 하였다[8]. PolyMG block을 기질로 사용하여 A vinelandii의 polyMG lyase를 반응시키고 ${ }^{1} \mathrm{H}-\mathrm{NMR}$ 로 분석한 결 과 $\mathrm{KJ}-2$ polyMG lyase와 달리 AlyA1, AlyA2 및 AlyA3 모두 가 $\mathrm{G}_{\mathrm{red} \beta}$ peak는 증가하는 반면 $\mathrm{M}_{\mathrm{red} \beta}$ peak는 거의 보이지 않아 M- $\beta(1-4)-G$ 결합보다는 G-a(1-4)-M 결합을 분해하는 효 소라고 보고하였다[8].

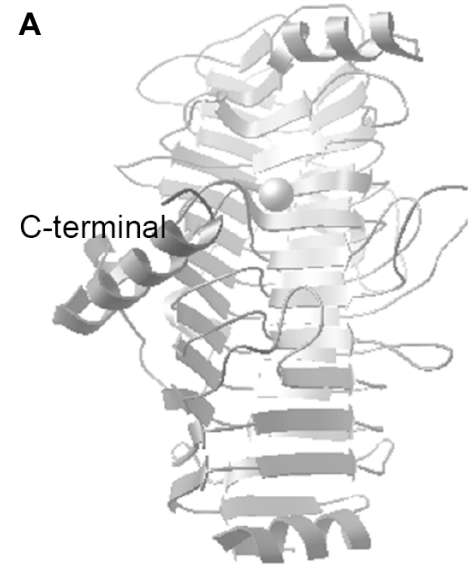

N-terminal
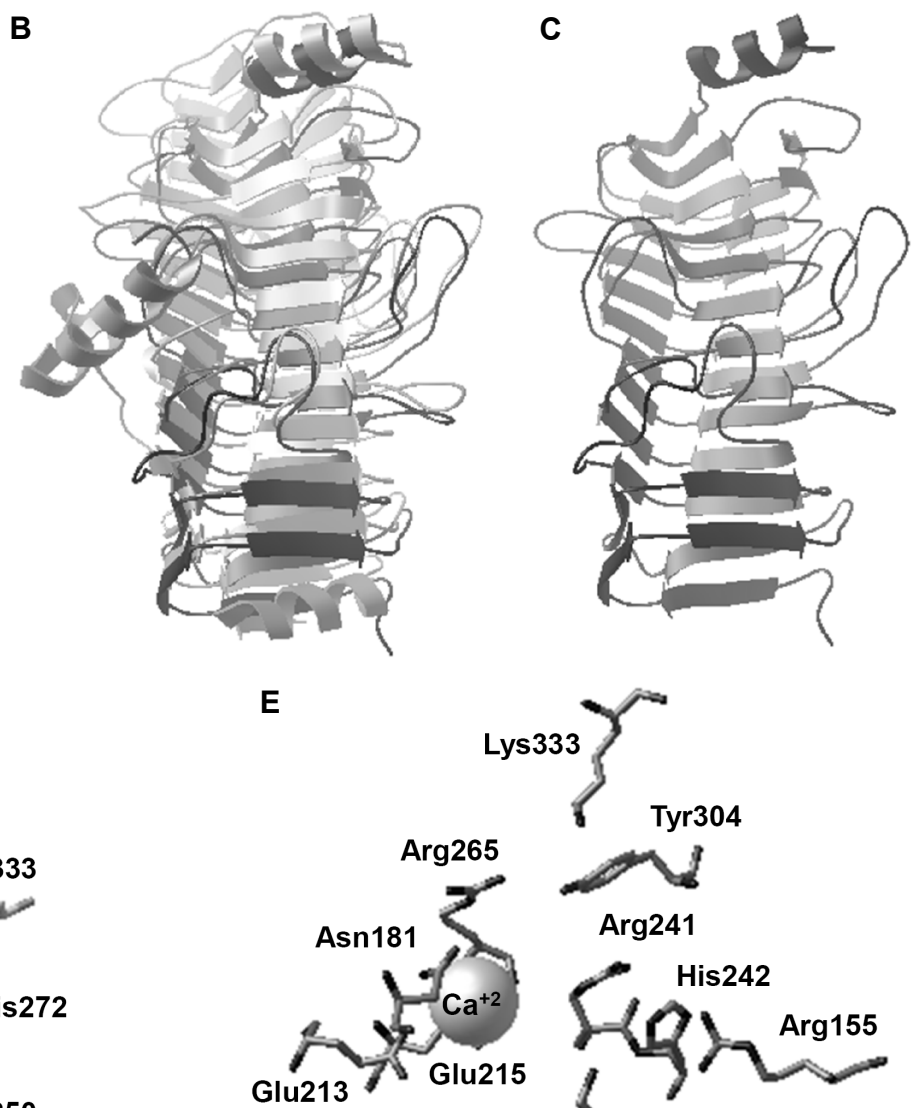

Arg241
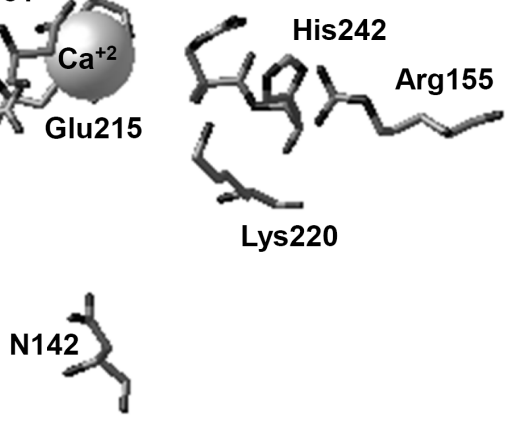

Fig. 3. Homology modeling of KJ-2 polyMG lyase based on crystal structure of chondroitinase B from Pedobacter heparinus. A: crystal structure of chondroitinase B (1ofl.pdb), B: homology model of KJ-2 polyMG lyase by using Modeller 7v7 program, C: superimposed KJ-2 polyMG lyase model on the crystal structure of chondroitinase B, D: active sites and substrate binding sites of chondroitinase B, and E: proposed active sites of KJ-2 polyMG lyase. 


\section{$\mathrm{KJ}-2$ polyMG lyase의 상동성 모델 및 활성자리 예측}

$\mathrm{KJ}-2$ polyMG lyase 단백질의 3차 입체구조를 예측하기 위 하여 P. heparinus의 chondroitinase B 결정구조(1ofl.pdb, Fig $3 \mathrm{~A})[20]$ 를 기질로 하여 상동성 모델링을 한 결과는 Fig. 3B와 같았다. PolyMG lyase의 단백질 서열을 SwissModel Workspace에서 3-D 입체구조 자동예측장치로 예측하였을 때 Azotobacter vinelandii mannuronan C-5 epimerase AlgE의 A-module (pdb code: $2 \mathrm{pyh}$ )[24]과 $12.7 \%$ 상동성을 가지는 것 으로 나타났으며 PL 6 family인 right handed $\beta$-helix구조를 가지는 것으로 예측되었으나 $\mathrm{AlgE}$ 의 활성자리와 polyMG lyase의 활성자리가 겹치지 않았으며 또한 polyM block에 KJ-2 polyMG lyase를 반응시켰을 때 mannuronate를 guluronate로 이성화시키는 epimerase 활성을 나타내지 않았다 (data not shown). KJ-2 polyMG lyase 단백질 서열을 결정구 조가 보고된 P. heparinus의 chondroitinase B 단백질 서열과 PSI- blastp 하였을 때 Fig. 4와 같이 454개의 아미노산 서열 중 18-345 아미노산 서열만이 이중정렬되었다. 이중정렬된 서 열을 이용하여 Modeller 7v7 program에서 상동성 모델링을 한 결과 Fig. $3 \mathrm{~B}$ 와 같은 모델을 얻었으며 주형으로 삼은 chondroitinase $B$ 와 겹쳐보았을 때 Fig. 3C와 같이 N-teminal과 C-terminal의 a-helix를 제외(blastp가 안된 부분)한 모든 부 분이 잘 겹쳐지는 것을 알 수 있었다(Fig. $3 \mathrm{D}, \mathrm{Fig} .3 \mathrm{E}$ ). PolyMG lyase의 Asn181, Glu213, Glu215, Lys220, His242, 및 $\mathrm{Arg} 241$ 잔기들의 측쇄가 chondroitinase B의 활성자리 및 기질 결합부위인Asn213, Glu243, Glu245, Lys250, His272 및 $\operatorname{Arg} 271$ 잔기의 측쇄들과 겹치는 것을 관찰할 수 있었으며 chondroitinase B의 Arg184, Glu333 및 Arg364에 해당하는 아미노산 잔기는 없었으나 polyMG lyase의 상동성 모델을
볼 때 단백질 표면에 존재하는 $\operatorname{Arg} 155, \mathrm{Tyr} 304$ 및 Lys333잔기 들이 활성자리 또는 기질결합에 관여할 것으로 생각되었다. 이제까지 보고된 알긴산 분해효소들을 살펴보면 polyM lyase 는 주로 (a/a)6 barrel 구조를 가지는 PL5 family에 속하며 Asn, His, Arg 및 Tyr 이 활성자리이고 그 중 Asn, His 및 Tyr이 catalytic triad로 작용한다고 하였다[32]. 반면 polyG lyase는 주로 $\beta$-jelly roll 구조를 가지는 PL7 family에 속하며 $\mathrm{Gln}, \mathrm{His}, \mathrm{Arg}$ 및 $\mathrm{Tyr}$ 잔기가 활성자리이고 그 중 $\mathrm{Gln}$, His 및 Tyr 잔기가 catalytic triad로 작용한다고 하였으며[29], 몇 몇 알긴산 분해효소들, 즉, P. aeruginosa의 PA1167 단백질[28] 및 $A$. vinelandii 의 polyMG lyase 단백질들[8]은 PL7 family 이면서도 polyM lyase 활성 또는 polyMG lyase 활성을 나타 내기도 하였다. 이와 같이 이제까지 보고된 알긴산 분해효소 들은 Asn 또는 $\mathrm{Gln}$ 과 같이 amide 측쇄를 가진 아미노산과 함께 His, Arg 및 Tyr이 활성자리를 구성하고 있었다[15, 29, 32]. 그러나 Fig. $3 \mathrm{~B}$ 에서와 같이 예측된 $\mathrm{KJ}-2$ lyase는 PL6 family에 속하는 chondroitinase $\mathrm{B}$ 의 결정구조와 비슷한 parallel $\beta$-helix 구조로서 이제까지 보고된 polyM lyase 및 polyG lyase의 구조와는 다르며 $\mathrm{Ca}^{+2}$ 이온을 가지는 metalloprotein 으로서 Arg 및 Lys 같은 염기성 아미노산이 풍부하여 산성다 당류인 알긴산 기질의 카르복실 음이온과 결합하는데 관여할 것으로 생각된다.

\section{Site-directed mutagenesis를 이용한 polyMG lyase mutant들의 효소활성}

KJ-2 lyase 단백질의 3-D 구조(Fig. 3B)를 예측하기 위하여 chondroitinase B 결정구조에 해당하는 아미노산 서열(1ofl)과 비교한 것은 Fig. 4 와 같았다. N-terminial 부분과 C-terminal

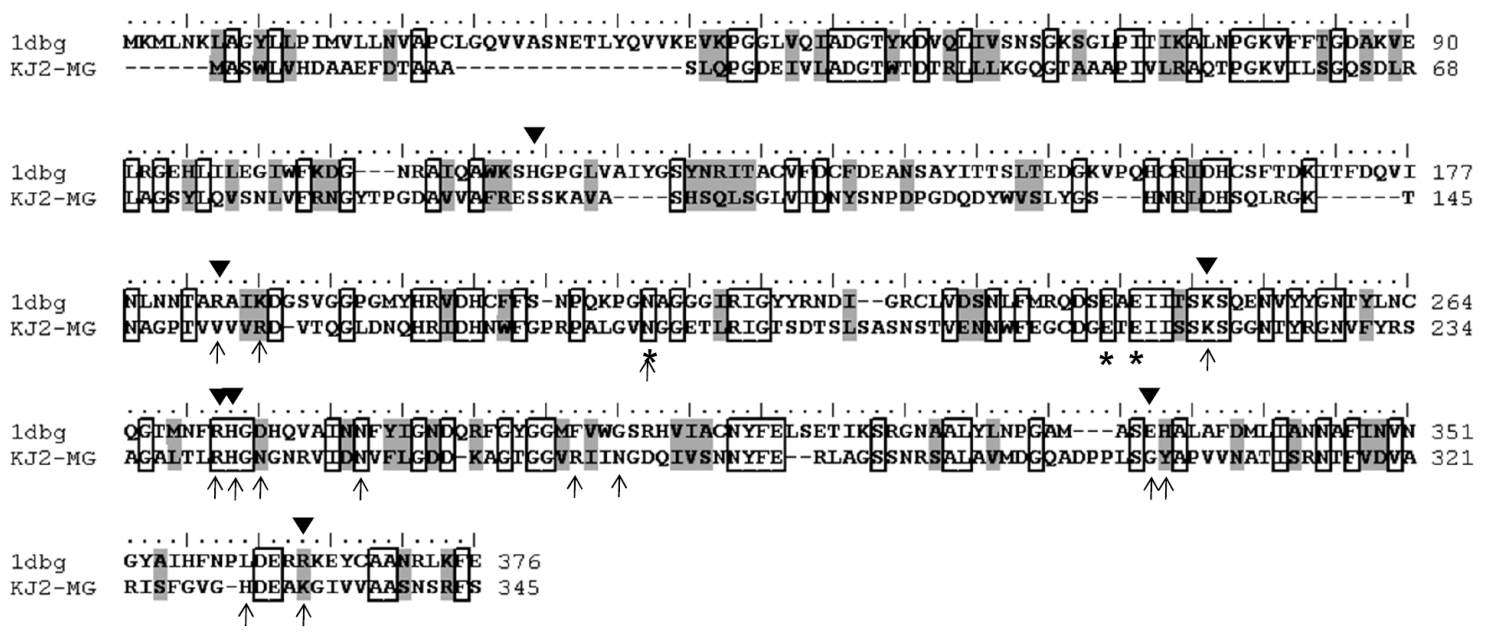

Fig. 4. Amino acid sequence alignment of partial KJ-2 polyMG lyase with chondroitinase B (1ofl.pdb) from Pedobacter heparinus by PSI-blastp method. Asterisks under the sequences represent the $\mathrm{Ca}^{+2}$ binding sites. Downward triangles indicate the proposed active sites and substrate binding sites of chondroitinase B. Upward arrows under the sequences indicate the amino acid residues mutated by site-directed mutagenesis. Outlined and shadowed boxes indicate identical and similar amino acid residues, respectively. 


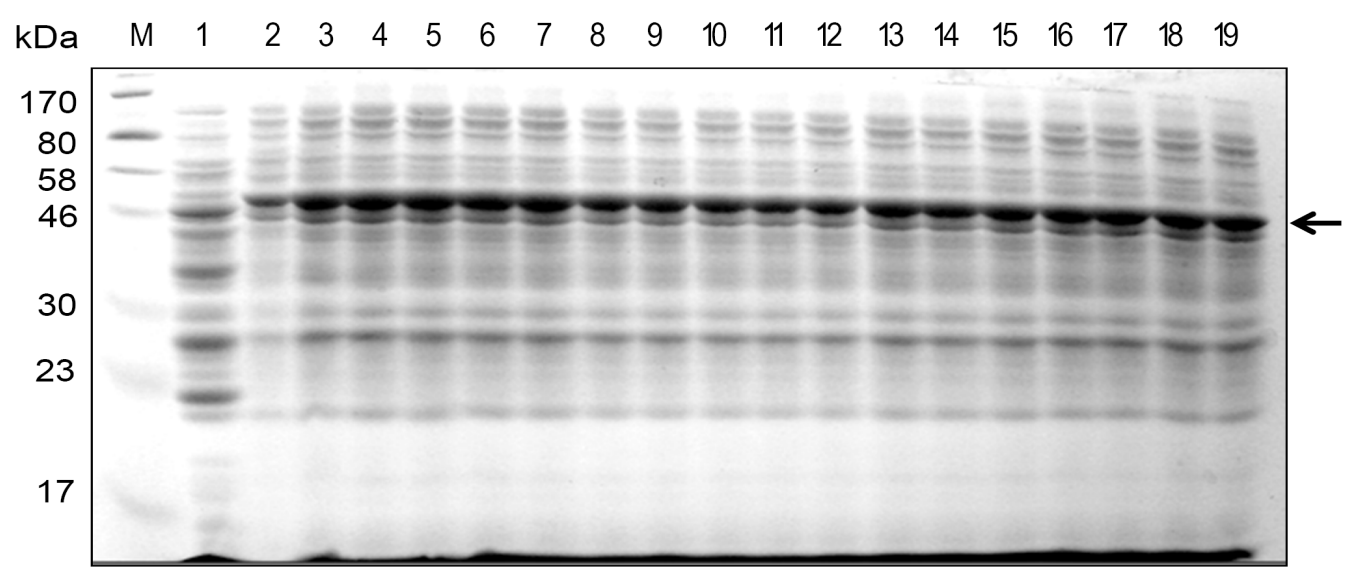

Fig. 5. $12 \%$ SDS-PAGE analysis of the recombinant $\mathrm{KJ}-2$ polyMG lyase mutants. The recombinant cells were cultured at $15^{\circ} \mathrm{C}$ for $24 \mathrm{~h}$ with or without $0.7 \mathrm{mM}$ IPTG. The cell lysates were obtained by thawing and freezing cells suspended with lysozyme solution. Arrow indicates the expressed $\mathrm{KJ}-2$ alginate lyases. M : protein standareds, lane 1: BL21 cells with pET21b $(+)$ vector only, lane 2: BL21 cells with pET21b(+)/KJ-2 polyMG lyase wild type gene, lane 2 - lane 19: BL21 cells with pET21b(+)/KJ-2 polyMG lyase mutants described as Table 2 .

부분의 a-helix 구조는 예측할 수 없었으므로 454 아미노산 중 18-345 아미노산까지를 비교하였으며 중요하다고 생각되 는 14군데의 아미노산 잔기(Fig. 4 서열아래 $\uparrow)$ 를 돌연변이시 켜 17 개의 돌연변이체를 얻었다. $\boldsymbol{\nabla}$ 는 Michel 등[20] 및 Huang 등[14]이 예측한 chondroitinase $\mathrm{B}$ 의 활성자리 또는 기 질 결합자리를 나타내며 *는 $\mathrm{Ca}^{+2}$ 이온과의 결합자리이며 $\uparrow$ 는 ployMG lyase의 활성자리 또는 기질과 결합할 것으로 예측되 어 돌연변이시킨 잔기들이다. PolyMG lyase의 wild type 및 17 개의 돌연변이 유전자들을 함유한 재조합 대장균들을 ampicillin이 함유된 LB배지에 키운 다음 IPTG로 단백질발현을 유도시키고 lysozyme용액을 처리함으로서 세포용해액을 얻 었다. $12 \%$ SDS-PAGE 전기이동법으로 단백질 발현을 확인한 다음 polyM, polyG 및 $\mathrm{MG}$ block을 기질로 하여 효소활성을
측정하였다. Fig. 5에서와 같이 KJ-2 알긴산 분해효소의 wild type 및 돌연변이체들의 단백질 발현은 비슷한 수준이었다. 그러나 cell lysate들의 효소활성을 wild type과 비교하였을 때 Lys220Ala mutant는 alginate lyase 활성이 완전히 소멸되 었으나 Lys220Arg의 경우 활성이 거의 유지되었다(Fig. 6). 그 러나 Arg241 및 Arg265의 경우 중성인 Ala 또는 염기성인 Lys으로 대치하여도 활성은 소멸된 것으로 보아 Arg241 및 $\operatorname{Arg} 265$ 는 알긴산 분해활성에 중요한 역할을 하는 것으로 볼 수 있다. His242는 polyG lyase, polyM lyase 및 chondroitinase B의 활성자리에 해당하는 잔기임에도 His242Ala mutant의 효소활성에 변화가 없는 것으로 보아 KJ-2 polyMG lyase의 활성자리는 아닌 것으로 보인다. Chondroitinase B는 glycosaminoglycans (GAGs) 중 하나인 dermatan sulfate를

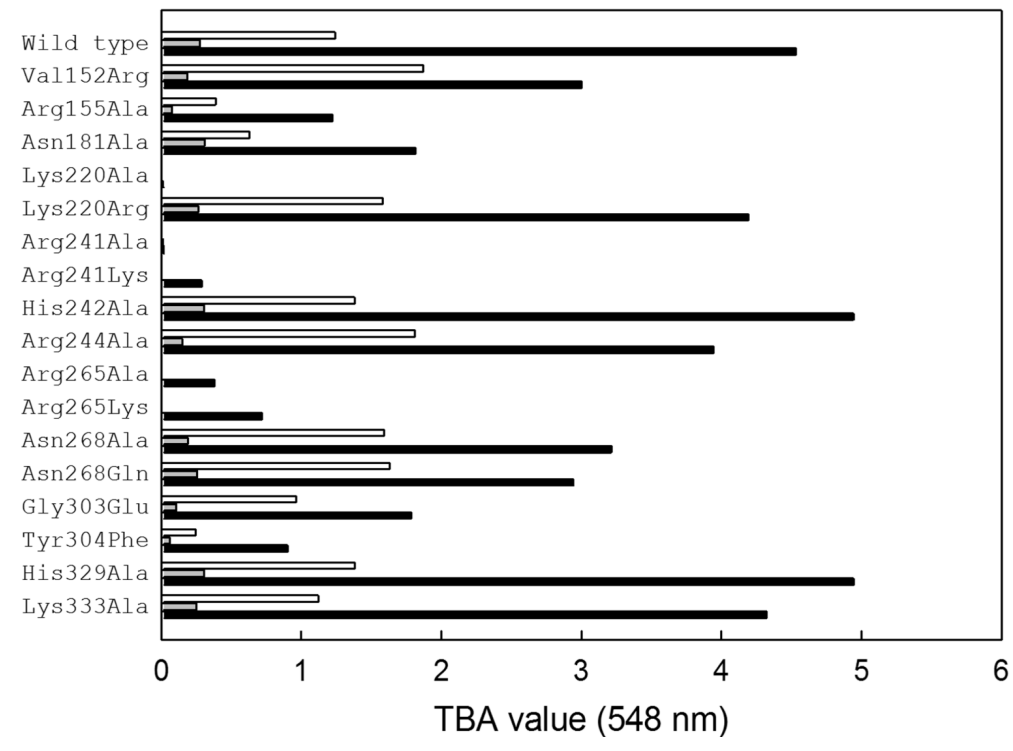

Fig. 6. Alginate lyase activities of KJ-2 polyMG-specific lyase mutants. Cell pellet of $10 \mathrm{ml}$ culture was lysed with $10 \mathrm{mM}$ lysozyme in 50 $\mathrm{mM}$ Tris- $\mathrm{HCl}$ ( $\mathrm{pH}$ 8.0). 0.2\% substrate solution was incubated with $20 \mu \mathrm{l}$ cell lysate in $20 \mathrm{mM}$ phosphate buffer $\left(\mathrm{pH} \mathrm{7.4)}\right.$ at $40^{\circ} \mathrm{C}$ for $30 \mathrm{~min}$ and boiled for removing the enzyme activity. Used substrates were polyM block (white bar), polyG block (gray bar) and polyMG block (black bar). 
분해하는 효소이며 dermatan sulfate는 D-N-acetylgalactos-

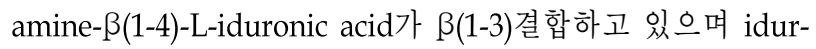
onic acid의 C2 위치와 galactosamine의 C4 위치에 고도로 황 산화되어 있는 선형 산성다당류이다. Huang 등[14]은 효소의 $\operatorname{Arg} 318$ 및 Arg364 잔기가 기질의 sulfate 부분과 결합하며 환 원 말단을 분해하는데 Glu333가 염기로서 작용하여 반응을 촉 매할 것으로 예측하였다. PolyMG lyase의 경우 Glu333에 해 당되는 위치의 Gly303을 Glu로 바꾸었으나 활성을 잃었으며 바로 옆의 Tyr304를 Phe로 돌연변이 시켰을 때 활성이 $80.1 \%$ 감소한 것으로 보아 알긴산 분해효소들의 활성자리로 알려져 있는 Tyr이 polyM lyase 또는 polyG lyase 등과 단백질 구조 는 다르지만 polyMG lyase활성에서도 활성자리로 작용할 것 으로 생각된다. Michel 등[20]은 chondroitinase $\mathrm{B}^{\text {는 }} \mathrm{Ca}^{+2}$ 이온 이 dimer로 분해되는 자리에 있는 L-iduronic acid의 carboxyl 기를 중화시키고 Lys250 및 Arg271이 각각 Brønsted 염기 및 산으로 작용하였다고 하였으며 KJ-2 polyMG lyase 역시 $\mathrm{Ca}^{+2}$ 이온과 Lys220 및 $\mathrm{Arg} 241$ 이 같은 역할을 했을 것으로 예측된 다. 또한 염기성 아미노산인 $\mathrm{Arg} 265$ 및 $\mathrm{Arg} 155$ 가 산성인 알긴 산 기질과 결합하여 분해작용을 하는데 중요한 역할을 할 것 으로 생각된다.

\section{감사의 글}

이 논문은 2013학년도 경성대학교 학술연구비지원에 의하 여 연구되었으므로 이에 감사드립니다.

\section{References}

1. Albrecht, M. T. and Schiller, N. L. 2005. Alginate lyase (AlgL) activity is required for alginate biosynthesis in Pseudomonas aeruginosa. J Bacteriol 187, 3869-3872.

2. ASTM International. 2010. ASTM F2259-10. Standard test method for determining the chemical composition and sequence in alginate by proton nuclear magnetic resonance (1H NMR) spectroscopy. Annual book of ASTM standards, Vol. 03.06. ASTM International, West Conshohocken, Penn., USA. Available from http://www.astm.org/Standards.

3. Beer, L. L., Boyd, E. S., Peters, J. W. and Posewitz, M. C. 2009. Engineering algae for biohydrogen and biofuel production. Curr Opin Biotechnol 20, 264-271.

4. Campa, C., Holtan, S., Nilsen, N., Bjerkan, T. M., Stokke, B. T. and SkJåk-Bræk, G. 2004. Biochemical analysis of the processive mechanism for epimerization of alginate by mannuronan C-5 epimerase AlgE4. Biochem J 381, 155-164.

5. Chisti, Y. 2008. Biodiesel from microalgae beats bioethanol. Trends Biotechnol 26, 126-131.

6. Cho, Y., Kim, H. and Kim, S. K. 2013. Bioethanol production from brown seaweed, Undaria pinnatifida, using $\mathrm{NaCl}$ acclimated yeast. Bioprocess Biosyst Eng 36, 713-719.

7. Gacesa, P. 1988. Alginates. Carbohydr Polym 8, 161-182.
8. Gimmestad, M., Ertesvåg, H., Heggeset, T. M., Aarstad, O., Svanem, B. I. and Valla, S. 2009. Characterization of three new Azotobacter vinelandii alginate lyases, one of which is involved in cyst germination. J Bacteriol 191, 4845-4853.

9. Grasdalen, H. 1983. High-field, 1H-n.m.r. spectroscopy of alginate: sequencial structure and linkage conformations. Carbohydr Res 118, 255-260.

10. Hashimoto, W., Miyake, O., Momma, K., Kawai, S. and Murata, K. 2000. Molecular identification of oligoalginate lyase of Sphingomonas sp. strain A1 as one of the enzymes required for complete depolymerization of alginate. $J$ Bacteriol 182, 4572-4577.

11. Haug, A. and Larsen, B. 1962. Quantitative determination of the uronic acid composition of alginates. Acta Chem Scand 16, 1908-1918.

12. Haug, A., Larsen, B. and Smidsrød, O. 1967. Studies on the sequence of uronic acid residues in alginic acid. Acta Chem Scand 21, 691-704.

13. Heyraud, A., Colin-Morel, P., Girond, S., Richard, C. and Kloareg, B. 1996. HPLC analysis of saturated or unsaturated oligoguluronates and oligomannuronates: Application to the determination of the action pattern of Haliotis tuberculata alginate lyase. Carbohydr Res 291, 115-126.

14. Huang, W., Matte, A., Li, Y., Kim, Y. S., Linhardt, R. J., $\mathrm{Su}, \mathrm{H}$. and Cygler, M. 1999. Crystal structure of chondroitinase B from Flavobacterium heparinum and its complex with a disaccharide product at $1.7 \mathrm{~A}$ resolution. $J \mathrm{Mol}$ Biol 294, 1257-1269.

15. Kam, N., Park, Y. J., Lee, E. Y. and Kim, H. S. 2011. Molecular identification of a polyM-specific alginate lyase from Pseudomonas sp. strain KS-408 for degradation of glycosidic linkages between two mannuronates or mannuronate and guluronate in alginate. Can J Microbiol 57, 1032-1041.

16. Kim, H. S., Lee, C. G. and Lee, E. Y. 2011. Alginate lyase: Structure, property, and application. Biotechnol Bioproc Eng 16, 843-851.

17. Kim, D. E., Lee, E. Y. and Kim, H. S. 2009. Cloning and characterization of alginate lyase from a marine bacterium Streptomyces sp. ALG-5. Mar Biotechnol 11, 10-16.

18. Lee, S. I., Choi, S. H., Lee, E. Y. and Kim, H. S. 2012. Molecular cloning, purification, and characterization of a novel polyMG-specific alginate lyase responsible for alginate MG block degradation in Stenotrophomonas maltophilia KJ-2. Appl Microbiol Biotechnol 95, 1643-1653.

19. Lombard, V., Bernard, T., Rancurel, C., Brumer, H., Coutinho, P. M. and Henrissat, B. 2010. A hierarchical classification of polysaccharide lyases for glycogenomics. Biochem $J$ 432, 437-444.

20. Michel, G., Pojasek, K., Li, Y., Sulea, T., Linhardt, R. J., Raman, R., Prabhakar, V., Sasisekharan, R. and Cygler, M. 2004. The structure of chondroitin B lyase complexed with glycosaminoglycan oligosaccharides unravels a calciumdependent catalytic machinery. J Biol Chem 279, 3288232896.

21. Momma, K., Okamoto, M., Mishima, Y., Mori, S., Hashimoto, 
W. and Murata, K. 2000. A novel bacterial ATP-binding cassette transporter system that allows uptake of macromolecules. J Bacteriol 182, 3998-4004.

22. Osawa, T., Matsubara, Y., Muramatsu, T., Kimura, M. and Kakuta, Y. 2005. Crystal structure of the alginate (poly alpha-l-guluronate) lyase from Corynebacterium sp. at $1.2 \mathrm{~A}$ resolution. J Mol Biol 345, 1111-1118.

23. Park, H. H., Kam, N., Lee, E. Y. and Kim, H. S. 2012. Cloning and characterization of a novel oligoalginate lyase from a newly isolated bacterium Sphingomonas sp. MJ-3. Mar Biotechnol 14, 189-202.

24. Rozeboom, H. J., Bjerkan, T. M., Kalk, K. H., Ertesvåg, H., Holtan, S., Aachmann, F. L., Valla, S., Dijkstra, B. W.. 2008. Structural and mutational characterization of the catalytic A-module of the mannuronan C-5-epimerase AlgE4 from Azotobacter vinelandii. J Biol Chem 283, 23819-23828.

25. Wargacki, A. J., Leonard, E., Win, M. N., Regitsky, D. D., Santos, C. N., Kim, P. B., Cooper, S. R., Raisner, R. M., Herman, A., Sivitz, A. B., Lakshmanaswamy, A., Kashiyama, Y., Baker, D. and Yoshikuni, Y. 2012. An engineered microbial platform for direct biofuel production from brown macroalgae. Science 335, 308-313.

26. Weissbach, A. and Hurwitz, J. 1959. The formation of 2-keto-3-deoxyheptonic acid in extracts of Escherichia. J Biol Chem 234, 705-709.

27. Wong, T. Y., Preston, L. A. and Schiller, N. L. 2000. Alginate lyase: Review of major sources and enzyme characteristics, structure-function analysis, biological roles, and applications Annu Rev Microbiol 54, 289-340.

28. Yamasaki, M., Moriwaki, S., Miyake, O., Hashimoto, W., Murata, K. and Mikami, B. 2004. Structure and function of a hypothetical Pseudomonas aeruginosa protein PA1167 classified into family PL-7: a novel alginate lyase with a beta-sandwich fold. J Biol Chem 279, 31863-31872.

29. Yamasaki, M., Ogura, K., Hashimoto, W., Mikami, B. and Murata K. 2005. A structural basis for depolymerization of alginate by polysaccharide lyase family-7. J Mol Biol 352, 11-21.

30. Yanagisawa, M., Kawai, S. and Murata, K. 2013. Strategies for the production of high concentrations of bioethanol from seaweeds: production of high concentrations of bioethanol from seaweeds. Bioengineered 4, 224-235.

31. Yeon, J. H., Lee, S. E., Choi, W. Y., Kang, do H., Lee, H. Y. and Jung, K. H.. 2011. Repeated-batch operation of surface-aerated fermentor for bioethanol production from the hydrolysate of seaweed Sargassum sagamianum. J Microbiol Biotechnol 21, 323-331.

32. Yoon, H. J., Mikami, B., Hashimoto, W. and Murata, K. 1999 Crystal structure of alginate lyase A1-III from Sphingomonas species A1 at 1.78 A resolution. $J$ Mol Biol 290, 505-514.

33. Zhang, Z., Yu, G., Guan, H., Zhao, X., Du, Y., and Jiang, $X .2004$. Preparation and structure elucidation of alginate oligosaccharides degraded by alginate lyase from Vibrio sp. 510. Carbohydr Res 258, 187-197.

\title{
초록 : Stenotrophomonas maltophilia KJ-2 균주로부터 얻은 PolyMG-specific 알긴산분해효소의 상동성 모델링 및 활성자리 연구
}

\author{
김희숙* \\ (경성대학교 공과대학 식품생명공학과)
}

알긴산은 a-L-guluronic acid와 $\beta$-D-mannuronic acid가 (1-4) 결합한 선형 산성다당류이다. 알긴산은 다양한 알 긴산 분해효소들에 의하여 분해되는데 $\beta$-제거반응으로 비환원 말단에 이중결합이 있는 불포화 우론산 올리고머 가 생산된다. 본 연구실에서는 이전에 Stenotrophomonas maltophilia KJ-2로부터 새로운 구조를 가진 polyMG lyase 를 재조합하였다. KJ-2 polyMG lyase의 단백질구조를 예측하기 위하여 상동성 모델링을 한 결과 Azotobacter vinelandii 가 생산하는 세 종류의 polyMG lyase들이 모두 PL7 family에 속하는 반면 KJ-2 polyMG lyase는 PL6 family에 속하였다. 또한 ${ }^{1} \mathrm{H}-\mathrm{NMR}$ spectra를 분석한 결과 polyMG lyase는 M- $\beta(1-4)-\mathrm{G}$ 당쇄결합을 분해하고 G-a (1-4)-M 결합은 거의 분해하지 못하는 것으로 나타났다. 예측된 polyMG lyase 모델을 기초로 하여 14 군데 아미노 산 잔기를 선택하였으며 17 개의 돌연변이체를 만들어 알긴산 분해효소의 활성을 측정하였다. Lys220Ala, Arg241Ala, $\mathrm{Arg} 241 \mathrm{Lys}$ 및 Arg265Ala 돌연변이체들은 완전히 알긴산 분해효소의 활성을 잃었으며 Arg155Ala, Gly303Glu 및 Tyr304Phe 돌연변이체들의 분해활성은 19.1-39.3\%까지 감소하였다. 이러한 결과들로부터 Arg155, Lys220, Arg241, $\operatorname{Arg} 265, \mathrm{Gly} 303$ 및 Tyr304 들은 알긴산 분해효소의 촉매활성과 기질결합에 중요한 잔기들임을 알 수 있다. 